CUPAUAM. 17-1990, 203-217

\title{
VIDRIOS ROMANOS DEL MUSEO DE CIUDAD REAL
}

\author{
JoAQUin AURRECOECHEA FERNANDEZ \\ UNIVERSIDAD AUTONOMA DE MADRID
}

\section{Resumen}

Muchos son los objetos que, durante la época romana, fueron fabricados en vidrio, pero entre el conjunto destacan netamente los recipientes vítreos. En este artículo, se dan a conocer los hallazgos de este tipo, procedentes del Museo Provincial de Ciudad Real. La importancia de este lote de piezas, radica en el desconocimiento actual sobre estas producciones en el área castellano-manchega.

\section{Summary}

Many classes of glass objects were manufactured during the Roman period, but one class stands out : glass vessels. This work studies the finds of this type kept at the "Museo Provincial" in Ciudad Real. The importance of this assemblage lies in the current lack of information about these productions in the area of Castilla - La Mancha.

\section{INTRODUCCION}

El vidrio ha sido un tipo de material tradicionalmente desatendido por la arqueología hispanorromana, a pesar de la valiosa información de corte cronológico y comercial que nos ofrece. Este panorama ha ido cambiando en los últimos tiempos, hasta llegar a la situación actual, en la que se están dando a conocer importantes conjuntos de piezas de esta índole. Sumándonos a esta corriente, presentamos la colección de vidrios romanos depositada en el Museo Provincial de Bellas Artes de Ciudad Real, que si bien es relativamente modesta, tiene el interés de pertenecer a un área geográfica para la que no existe ningún estudio relativo a estos objetos.

La colección está formada exclusivamente, por los materiales procedentes de la antigua colección de D. Eduardo Tello y los hallados en las excavaciones de La Bienvenida (Almodóvar del Campo). Para los primeros contamos, en ocasiones, con alguna referencia a su localización originaria, aunque desconocemos las circunstancias de su hallazgo. Los segundos están relacionados con las excavaciones científicas en curso que se realizan en el hábitat antes citado, aunque su adscripción a una zona de revuelto y su pertenencia a niveles superficiales, les sustrae de la estra- 
tigrafía general del yacimiento. Como se puede observar, tanto para unos como para otros, carecemos de otro marco de referencia que no sea el inherente al objeto en sí, por lo que las conclusiones a las que podemos llegar, estarán basadas en las afinidades tilógicas y morfológicas que presenten con otros materiales conocidos.

Han sido excluidos de este estudio los objetos relacionados con el adorno personal, ya que presentan una problemática específica derivada de la inmutabilidad de las técnicas formativas y decorativas, lo que dificulta enormemente el dotar a estas piezas de un marco temporal válido, cuestión que se complica, en nuestro caso, al ser todas nues tras piezas descontextualizadas. También han quedado apartados de la investigación los removedores de perfumes procedentes de la necrópolis de Alhambra, dados ya a conocer (Alonso, 1986-87, 11). Respecto a los materiales de La Bienvenida, hemos sido selectivos a la hora de su publicación, dejando a un lado multitud de pequeños fragmentos sumamente exiguos como para identificar forma alguna. En casos concretos, como los cuencos decorados con costillas, hemos procedido a recoger los ejemplares más completos, aunque queremos dejar constancia de la apa rición de otros muchos reducidos a fragmentos ínfimos.

El trabajo se estructura en dos bloques: la presentación del catálogo y el estudio de los materiales. En este último apartado nos hemos ceñido principalmente a la clasificación topológica de Isings y Morin-Jean, completando la labor con la referencia a materiales de cronología definida y a los paralelos hallados en la Península Ibérica.

\section{CATALOGO}

Núm. 1: Jarra de vidrio transparente, color beige melado. Procedente de la colección E. Tello, hallada en Alhambra. Cuerpo ovoide, cuello cilíndrico que se abre en una boca con forma de embudo. Borde exvasado de tendencia elíptica. Pie anular con doblez y umbo central. Presenta como elemento de prehensión un asa lisa de sección rectangular. Diámetro de la base. $5 \mathrm{~cm}$. Altura: $16,1 \mathrm{~cm}$.

Núm. 2: Jarra de vidrio color beige melado, con irisaciones azulado-rosáceas. Procedente de la colección E. Tello, hallada en Porzuna la Vieja. Fragmento de pared convexa, hasta lo conservado. Cuello cilíndrico, con boca de embudo. Borde exvasado y engrosado. Asa lisa de sección circular. Diámetro: $4,2 \mathrm{~cm}$. Altura conservada: $9,2 \mathrm{~cm}$.

Núm. 3: Jarra de vidrio color verde claro. Procedente de La Bienvenida. Fragmento de borde exvasado y engrosado. Asa lisa de sección rectangular. Diámetro: $6,1 \mathrm{~cm}$.

Núm. 4: Botella de vidrio color azul verdoso. Procedente de La Bienvenida. Fragmento de cuello cilíndrico y grueso borde, exvasado y doblado sobre sí mismo, formando un reborde interno. Diámetro interior: $3,5 \mathrm{~cm}$.

Núm. 5: Botella de vidrio color azul verdoso. Procedente en La Bienvenida. Fragmento de base moldeada, con restos de un motivo circular.Grosor: $0,3 \mathrm{~cm}$.

Núm. 6: Botella de vidrio color azul verdoso. Procedente de La Bienvenida. Fragmento de base moldeada, con restos de un motivo angular. Grosor: $0,4 \mathrm{~cm}$.

Núm. 7: Fragmento de borde exvasado y posteriormente doblado al interior. Vidrio de color azul verdoso. Procedente de LaBienvenida. Diámetro: $6 \mathrm{~cm}$.

Núm. 8: Fragmento de borde doblado al exterior y vuelto a doblar al interior, dejando una oquedad interna. Vidrio opaco de color blanco. Procedente de La Bienvenida. Diámetro: 3,8 cm. 
Núm. 9: Fragmento de borde exvasado y engrosado. Vidrio de color azulado. Procedente de La Bienvenida. Diámetro: $5 \mathrm{~cm}$.

Núm. 10: Ungüentario de vidrio color verde-azulado, con irisaciones azul-violáceo. Procedente de la colección E. Tello. Largo cuello cilíndrico con cuerpo bajo y ancho. Borde exvasado. Base lisa rehundida. Diámetro del borde: $2,1 \mathrm{~cm}$. Altura: 10,7 cm.

Núm. 11: Ungüentario de vidrio color verde. Procedente de la colección E. Tello. Cuello cilíndrico con pequeño estrangulamiento infeferior, que da paso a un cuerpo piriforme. Borde desaparecido. Altura conservada: $9,4 \mathrm{~cm}$.

Núm. 12: Ungüentario de vidrio color azul claro. Procedente de La Bienvenida. De él sólo se conserva la boca troncocónica y el labio incurvado. Diámetro: $2,6 \mathrm{~cm}$.

Núm. 13: Ungüentario de vidrio translúcido. Procedente de La Bienvenida. Como el número anterior, sólo que con borde exvasado y doblado. Diámetro: $3,3 \mathrm{~cm}$.

Núm. 14: Ungüentario de vidrio translúcido con irisaciones verde-azuladas. Procedente de la colección E. Tello. Vasito de cuerpo ovoide cuello exvasado. Base plana con umbo central. Diámetro del borde: $3,3 \mathrm{~cm}$. Altura: $3,6 \mathrm{~cm}$.

Núm. 15: Cáliz de vidrio color verde-azulado, con irisaciones nacaradas. Procedente de la colección E. Tello, hallado en Alhambra. Fragmento de un cáliz, del que sólo se conserva el pie, estando éste compuesto por un vástago hueco de forma cilíndrica y una base discoidal rebajada. Diámetro: $4 \mathrm{~cm}$.

Núm. 16: Cántharos de vidrio color verde oscuro. Procedente de La Bienvenida. Como en el caso anterior, el único resto conservado es el pie macizo, compuesto de un vástago en forma de bola achatada y una base discoidal. Diámetro: $5,6 \mathrm{~cm}$.

Núm. 17: Cuenco de costillas de vidrio color azul verdoso. Procedente de La Bienvenida. Fragmento de borde exvasado y cuerpo decorado con costillas. Diámetro: indeterminado.

Núm. 18: Cuenco de costillas de vidrio color azul. Procedente de La Bienvenida. Fragmento de borde y pared, semejante al número anterior. Diámetro: indeterminado.

Núm. 19: Vaso de vidrio color azul verdoso. Procedente de La Bienvenida. Borde recto, e inicio de cuerpo indeterminado. Diámetro: $19 \mathrm{~cm}$.

Núm. 20: Vaso de vidrio opaco de color blanco. Procedente de La Bienvenida. Borde ligeramente exvasado y restos de pared sinuosa. Diámetro: $17 \mathrm{~cm}$.

Núm. 21: Cuenco de vidrio color verde oscuro. Procedente de La Bienvenida. Fragmento de un recipiente de borde vertical engrosado y paredes abiertas. Pared decorada mediante una línea incisa. Diámetro: $15 \mathrm{~cm}$.

Núm. 22: Vaso de vidrio opaco de color blanco. Procedente de La Bienvenida. Fragmento de borde y pared de un recipiente cilíndrico. Decorado con hilos de vidrio. Diámetro: $9 \mathrm{~cm}$.

Núm. 23: Vaso de vidrio translúcido. Procedente de La Bienvenida. Semejante al anterior. Diámetro: $5 \mathrm{~cm}$.

Núm. 24: Taza de vidrio translúcido. Procedente de La Bienvenida. Fragmento de pared cilíndrica, decorada con un cordón de vidrio en la parte superior. Borde redondo engrosado. Diámetro: $11,2 \mathrm{~cm}$.

Núm. 25: Vaso de vidrio de color verde oscuro. Procedente de La Bienvenida. Fragmento de borde recto engroado y pared convexa. Diámetro: $7,2 \mathrm{~cm}$.

Núm. 26: Cuenco de vidrio translúcido. Procedente de La Bienvenida.Fragmento de borde doblado y pared redondeada. Diámetro: $8,8 \mathrm{~cm}$. 
Núm. 27: Cuenco de vidrio translúcido. Procedente de La Bienvenida.Semejante al anterior. Diámetro: $7,4 \mathrm{~cm}$.

Núm. 28: Recipiente de vidrio translúcido. Procedente de La Bienvenida. Fragmento de borde exvasado y engrosado. Diámetro: $10 \mathrm{~cm}$.

Núm. 29: Recipiente de vidrio translúcido. Procedente de La Bienvenida. Análogo al anterior. Diámetro: $8,6 \mathrm{~cm}$.

Núm. 30: Recipiente de vidrio translúcido. Procedente de La Bienvenida. Similar al anterior. Diámetro: 8,2 .

Núm. 31: Vaso de vidrio opaco de color blanco. Procedente de La Bienvenida. Fragmento de borde arqueado y pared indeterminada. Diámetro: $6,2 \mathrm{~cm}$.

Núm. 32: Vaso de vidrio opaco de color blanco. Procedente de La Bienvenida. Fragmento de borde doblado y pared de tendencia globular. Diámetro: $8,2 \mathrm{~cm}$.

Núm. 33: Vaso de vidrio translúcido. Procedente de La Bienvenida. Fragmento de borde exvasado y pared indeterminada. Diámetro: $8,8 \mathrm{~cm}$.

Núm. 34: Fragmento de recipiente de vidrio translúcido, decorado con depresiones elípticas longitudinales de diverso tamaño. Procedente de La Bienvenida.

Núm. 35: Fragmento de recipiente de vidrio opaco de color blanco, ornamentado con hilo de vidrio. Procedente de La Bienvenida.

Núm. 36: Fragmento de recipiente de vidrio translúcido, decorado con grueso hilo de vidrio. Procedente de La Bienvenida.

Núm. 37: Fragmento de recipiente de vidrio opaco de color blanco. Procedente de La Bienvenida. Fragmento de pared ornamentada con estrechos hilos de vidrio que forman motivos ondulados.

\section{ESTUDIO}

El número 1 de nuestro inventario se encuentra relacionado con el tipo 52 de Isings, en su variante $\mathrm{C}$, donde se engloban a las jarras de cuerpo ovoide, siendo éstas derivación de las jarras con cuerpo bulboso. La mayoría de los ejemplares conocidos: Gravellona, Premeno, etc., pertenecen al S. I d.C. (Isings, 1957, 71). Así mismo, se podría conectar con el grupo A de Calvi, de perfil semejante, pero carente de pie anular. Este grupo también estuvo muy difundido durante la primera centuria, siendo además una de las más antiguas formas de vidrio soplado (Calvi, 1968, 69). La variedad A, del tipo 50 de Morin-Jean, encaja con la jarra procedente de Alhambra, siendo la única discrepancia la ausencia de asa nervada, característica que presenta la forma de Morin (Morin-Jean, 1977, 104-109). Estos últimos recipientes se fechan en el S. II d.C. Todos los autores mencionados señalan la relativa escasez de este tipo de jarra, no conociendo, por nuestra parte, ningún paralelo peninsular exacto en la bibliografía consultada.

Las jarras 2 y 3 sólo es posible clasificarlas atendiendo a la forma del borde, ya que carecemos del cuerpo. Las bocas denominadas "embutiformes" comienzan a documentarse a partir del S. II d.C., aunque aparecen más frecuentemente en piezas tardías de los siglos III-

IV. Este tipo de bordes suele estar asociado a jarras de cuerpo piri forme con pie (forma Lancel 10) (Lancel, 1967, 15 y 52, núm. 65), arras aplastadas (forma Lancel 11) (Lancel, 1967, 15 y 54, núm. 68) y a jarras de cuerpo globular (formas Isings 92 y 104) (Isings, 1957, 10, 123124). En Hispania tenemos ejemplares similares en Baetulo (Flos, 1987, 90, fig. 67, núm. 401403) y en la incineración Nofre-16e Ampurias, enterramiento fechado en época de Claudio (Almagro, 1955, 207, núm. 1). 
El número 4 del catálogo es un borde triangular perteneciente a un frasco de la forma Isings 102 o a una botella del tipo 50-51 de Isings, sin que podamos precisar más sobre su morfología. El que la forma Isings 51 tenga una reducida expansión por Occidente y además desaparezca en las postrimerías del segundo siglo de nuestra era, parece descartar esta adscripción tipológica para nuestro ejemplar. En nuestro país los bordes triangulares se datan desde fines del S. II al S. III d.C., si bien parece que en la Península Ibérica perviven hasta la centuria siguiente, como parece abalar el hallazgo de Alconétar (Caballero, 1970, 43, fig. 13, 54). De Baetulo podemos mencionar también varios paralelos conocidos (Flos, 1987, 43-44, fig. 13, núm.102 y 87, fig. 63, núm. 375).

Los fondos 5 y 6 pertenecen a botellas prismáticas, recipiente muy popular durante los siglos I-II d.C. Están recogidas con el número 50 de la tipología de Isings, que distingue el subtipo $50 \mathrm{a}$, donde se engloban las botellas bajas y anchas, y el subtipo 50b, de botellas altas y estrechas. Este último parece ser más tardío, aunque ambas disfrutaron de su momento álgido en época flavia y durante todo el S.II d.C. (Isings, 1957, 63-67), Morin-Jean desdobla esta forma en su tipo 14, botellas de base cuadrangular, y el 16 de base rectangular (Morin-Jean, 1977, 61-63); mientras que Lancel les adjudica los números 8 y 9 de su clasificación (Lancel, 1967, 15, fig. 10 y 11). Técnicamente se producían mediante dos métodos constitutivos, el soplado a molde o al aire, aplastándole a estas últimas los lados y el fondo hasta darle forma cúbica, siendo además las paredes de menor grosorpues servían para la vajilla de mesa (Charlesworth, 1966, 28). Para Isings las botellas sopladas al aire tendrían su origen en el área mediterránea, fijándose el momento inicial de su fabricación en el período flavio (Isings, 1957, 199). Las piezas ejecutadas con molde, como nuestros dos ejemplares, poseen unas paredes más gruesas, ya que estaban destinadas al transporte de líquidos, y suelen ostentar motivos decorativos diversos en la base, pudiendose interpretar algunos de ellos como marcas alusivas al taller (Alarcao, 1965, 90; Morin-Jean, 1977, 61). Son estas las botellas más comunes y para las que se ha fijado su foco matriz en el área egipcia, posiblemente en la zona alejandrina, en torno a la primera mitad del S. I d.C. (Flos, 1987, 89). En Camulodunum surgen en el período III (43-48 d.C.) (Harden, $1947,306)$, aunque para Isings la fecha inicial de su expansión en Occidente se deba situar posteriormente al 70 d.C. (Isings, 1957, 65). Permanecieron en uso durante los siglos II-III d.C., distinguiendose las de la segunda centuria por ser generalmente de vidrio azul verdoso, mientras que las del siglo III son de vidrio translúcido o amarillo verdoso (Morin-Jean, 1977, 62). En Colonia aparecen asociadas a contextos del S. IV d.C., si bien durante este siglo el tipo ya pasó a ser muy escaso (Isings, 1957, 65-67).

El estado fragmentario de la decoración conservada en nuestros dos ejemplares, nos permite realizar sólo algunas apreciaciones someras. Respecto al fragmento de ornamentación circular que caracteriza a la pieza número 5 , diremos que es este el motivo que aparece más representado entre estos recipientes, siendo a menudo la orla exterior que complementaba la decoración. Ante lo frecuente del tema citaremos únicamente algunos paralelos hispanos, como son los hallados en Baetulo (Flos, 1987, 189, fig. 66, 400) y Conímbriga (Alarcao. 1965, fig. 6, núm. 148, 150 y 151). Para el fondo número 6 contamos con una pieza similar hallada en Alicante (Sánchez de Prado, 1984, fig. 4, 7).

Los números 7 al 9 del catálogo son bordes pertenecientes a botellas como las anteriormente comentadas, sin que podamos añadir más datos debido al incompleto estado en que han llegado hasta nuestros días. Sólo para el número 7 queremos indicar un borde idéntico, correspondiente a una botella cilíndrica, aparecido en Badalona (Flos, 1987, 87, fig. 64, núm. 381). 
Con el número 10 hemos inventariado un ungüentario de candelero (forma Isings 82), denominación genérica de los balsamarios de largo cuello con cuerpo bajo y ancho. Según Vessberg se trata de un recipiente con gran difusión por el Mediterráneo Oriental y por el oeste de Europa, concretamente en el valle del Ródano, donde la concentración de hallazgos con marca de producción sugiere la existencia de un taller (Vessberg, 1952, 203). Estos ungüentarios sufrieron una evolución continua, lo que posibilita dividirlos en grupos morfológicos. Aquellos semejantes al nuestro, de tipo bulboso y perfil continuo, es decir carentes de división entre cuello y cuerpo, fueron muy populares tanto en Chipre, Egipto y Jerusalen, como en Colonia. En Chipre se documentan en el S. I d.C., aunque el mayor volumen de hallazgos se integra en la centuria siguiente (Calvi, 1968, 134). En Aquileia existe otro grupo muy nutrido, datable en el S. III d.C., por lo que tal vez allí tengamos que ubicar un centro productor (Calvi, 1968, 139). En Hispania han aparecido en Alicante, algunos fechados entre el S. II-S.III d.C. (Sánchez de Prado, 1984, 84, fig. 2, núm. 6-14); incineración número 10 de Segóbriga, datado posiblemente de Tito a Domiciano (Almagro, 1979, 234, fig. 18, núm. 10); sepultura número 1 de la necrópolis de Mahora (Albacete) (Roldan Gomez, 1986-87, 249, fig. 2, A), Carmona (Bendala, 1976, 114, lám. 47, núm. 16) y Mérida (Caldera, 1983, 4950, fig. 13 c).

El número 11 es un ungüentario tubular. Estos balsamarios de cuerpo piriforme alargado y base redonda, que casi no permiten la estabilidad de la base, son recogidos con el número 8 de la clasificación de Isings y el 15 de Lancel (Isings, 1957, 24; Lancel, 1967, 17). Desde el punto de vista cronológico fueron muy abundantes durante el S. I d.C., centrándose su origen en época julio-claudia, para hacerse muy populares con los flavios. De la necrópolis de Kreuznach, se conoce una sepultura en la que apareció un recipiente de este tipo asociado un cuenco de costillas,lo que abala la cronología inicial (Morin-Jean, 1977, 253, fig. 330). La fecha final de producción es dificil de precisar, pues aparecen en Karanis en contextos relativos a los siglos III-IV d.C. Isings desliga de este grupo a los ungüentarios tubulares que poseen estrangulamiento, característica compartida por el ejemplar de Ciudad Real, datándolos entre Augusto-Tiberio y Adriano-Antonino. Este subtipo tambíen perduró, en el Mediterráneo Oriental, durante la etapa tardía (Harden, 1936, 266). Según la forma del borde, se pueden distinguir los balsamarios con estrangulamiento pertenecientes al S. I d.C. y los tardiós, los primeros poseen borde en arista viva o ligeramente redondeada, mientras que los segundos presentan el borde dobladohacia el interior (Vessberg, 1956, 205). Al carecer nuestro ejemplar del borde, nos centraremos en la forma del cuerpo para intentar afinar su cronología. Alarcáo considera que los ungüentarios de la forma 8 de Isings, cuyo estrangulamiento se encuentra situado por encima de la mitad de altura, y semejantes por tanto al de la colección Tello, son característicos de la primera mitad del S. I d.C. (Alarcao, 1963a,182). Esta datación, propuesta por el investigador portugués, parece confirmarse al menos para los ejemplares hispanos conocidos, a tenor de los hallazgos que a continuación exponemos; en la necrópolis de incineración Torres, de Ampurias, encontramos en el ajuar de la sepultura 16 y en el de la 9 dos balsamarios de este tipo. El primer enterramiento ampuritano se encuentra fechado en época de Tiberio-Claudio, mientras que el segundo es de Claudio-Tito (Alarcao, 1955, 160, núm.21 y 150, núm. 5). En las tumbas 2, 16 y 20 de la necrópolis al sureste de Belo (Remesal, 1979, 19, fig. 6, 73/10; 27-28, fig. 20, 73/68-71; 31, fig. 25, 73/102), aparecieron piezas similares cuya cronología abarca desde Claudio a los flavios (Remesal, 1979, 46). Del S. I d.C., sin más precisiones, son dos ejemplares de Alcoy (Sánchez de Prado,1984, fig. 1, núm. 16 y 17), así como los de Baetulo (Flos, 1987, 97, fig. 72, núm. 443-444). De Claudio a Vespasiano se datan los especímenes de la incineración número 2 de 


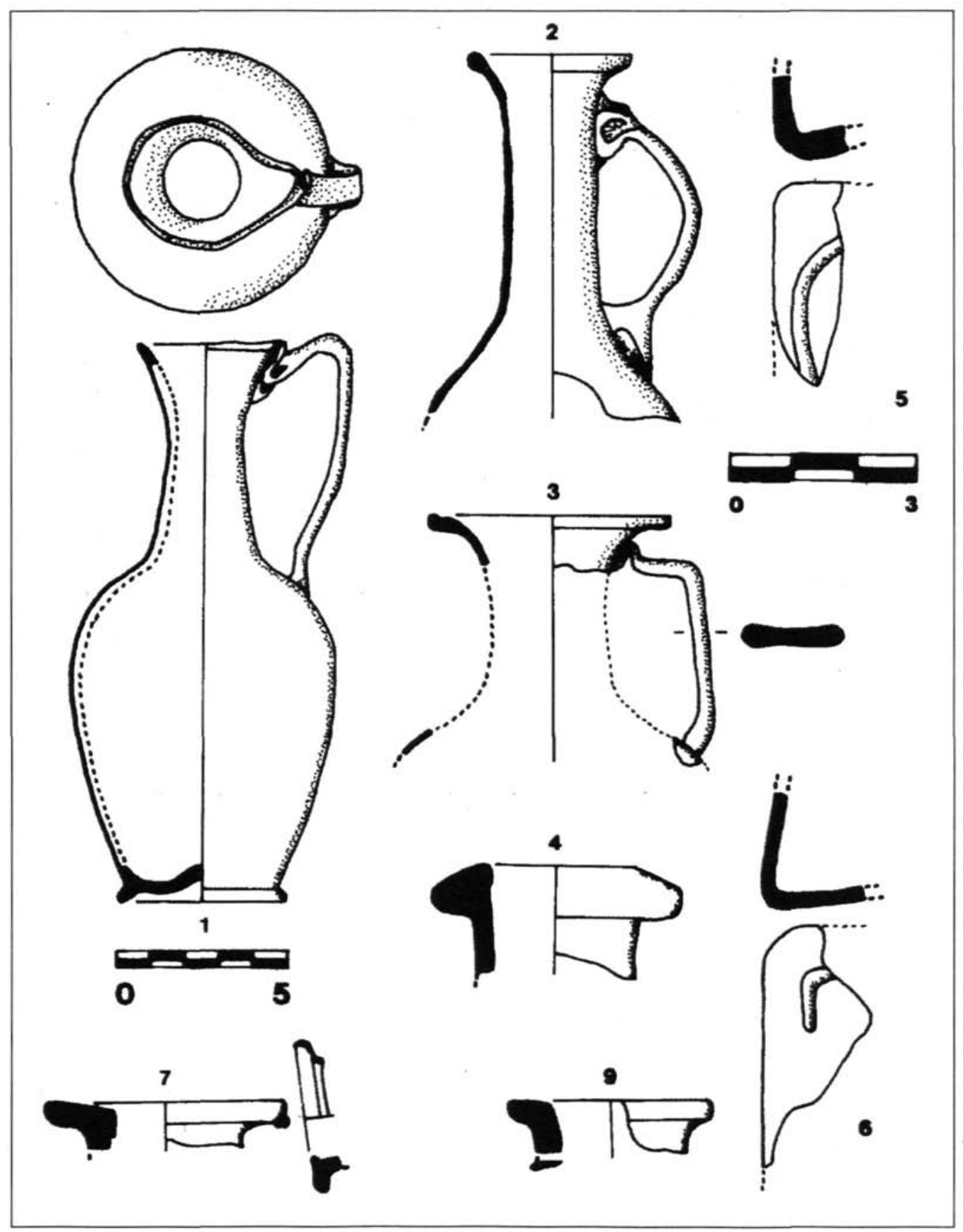

Figura 1.- Núm. 1 al 3, jarras procedentes de Alhambra, Porzuna la Vieja y La Bienvenida, respectivamente; Núms. 4 al 9, botellas y jarras de La Bienvenida. 
Segóbriga (Almagro, 1979, 222, fig.8, núm. 5 y 6). A la primera mitad de esta centuria, apuntan los ungüentarios lusos de la sepultura de Almeirim (Alarcao, 1963a, 180, fig. 6, núm. 3) y Alcácer do Sal, fechada esta última entre Claudio a Tito (Alarcao, 1963b, 380, fig. 1, núm. 4).

El fragmento número 12 del catálogo, pertenece a un borde de ungüentario del mismo tipo que la pieza anterior. El único aspecto de datación válido es por tanto la morfología de este elemento. Los bordes con características semejantes al nuestro se fechan en el S. I d.C., ya que en el siglo siguiente pasaron a ser triangulares. Bordes idénticos a este aparecen en los ungüentarios de Alcoy, incineraciones de las necrópolis Torres y la sepultura 16 de Belo, paralelos todos ellos ya comentados.

Del ejemplar número 13 no podemos precisar con exactitud a que pieza pertenecía el fragmento, si bien podemos decir que este tipo de boca se aplicó sobre ampollas, jarras de largo cuello, etc. En general son formas similares a las de los ungüentarios, pero de mayores dimensiones, inscritas en los tipos 26 y 39 de Morin Jean (Morin-Jean, 1977, 79-91).Para este autor estas piezas se situan cronológicamente entre los siglos III-IV d.C, aunque Flos piensa que al existir ungüentarios con este tipo de boca a finales del S. II, hace posible que ladatación inicial sea algo anterior (Flos, 1987, 91).

En el número 14 tenemos representado un ungüentario olleiforme, perteneciente a la forma 68 de Isings. Se tratan de pequeños vasos globulares sin pie, similares a las urnas Isings 67a. La función que se les adjudica es la de contenedora de ungüentos, ya que en ocasiones se han encontrado recipientes de este tipo con varillas removedoras de bronce en su interior (Isings. 1957, 88). Esta utilidad, sin embargo, es desmentida por algunos investigadores, como Calvi, para quien sólo se tratan de vasos de uso dómestico (Calvi, 1968, 31). Calvi los clasifica dentro su grupo $\mathrm{C}$ de balsamarios, dividiéndolos según la forma del borde, perteneciendo nuestro ejemplar a la variante alfa, datadadesde fines del S. I al S. II d.C. (CalviI, 1968, 31-32). Cronológicamente son muy abundantes en época flavia y durante todo el S. II d.C., aunque su origen debe ser anterior, pues en Conímbriga aparecen con Claudio (Alarcao, 1963b, documentándose también en Pompeya, realizados en vidrio mosaico (Borriello, 1986, 220, núm. 14). Así mismo en la incineración Patel-18 de Ampurias apareció un ejemplar inscrito en un contexto de Tiberio a Claudio (Almagro, 1955, 245, núm. 9). Otros paralelos peninsulares son los de Baetulo (Flos, 1987, 94, fig. 70, núm.421-422), el hallado dentro del sarcófago de plomo de la sepultura número 1 de Ucubi (Espejo, Córdoba), cuya datación se sitúa en la segunda mitad del S. I d.C. (Marcos Pous, 1988, 195, fig. 3.4 y 4.4), Carmona (Bendala, 1976, 115, lám. 48, núm. 16), Museo Bíblico de Montserrat (Villalba, 1983-84, 219, núm. 102) y Mérida (Caldero, 1983, 48, fig. 12 e).

La pieza número 15 es un pie de cáliz atribuible a la forma 111 de Isings (Isings, 1957, 40). Este tipo estuvo en uso durante los siglos IV-V d.C., siendo su zona de difusión preferente la parte oriental del Imperio, mientras que en Occidente son escasos, debido a la popularidad de los vasos troncocónicos lisos o decorados con cabujones, característicos también de este período (Vessberg, 1956, 199). Cálices semejantes al nuestro, con pie tubular y base vaciada encontramos, porejemplo en Karanis (Harden, 1936, 167-168), Baetulo (Flos, 1987, 50, fig. 20, núm. 33) y Conímbriga (Alarcao, 1965, 134, fig. 10, núm.255).

El número 16 es un cantharos de la forma 38 de Isings, sin que podamos precisar con seguridad la variante morfológica a la que pertenenece, debido a las reducidas dimensiones del fragmento. Su temporalidad fué breve, abarcando exclusivamente el S. I d.C., estando centrada su época de apogeo desde la mitad de esta centuría hasta el final, no sobreviviendo al nuevo siglo. 


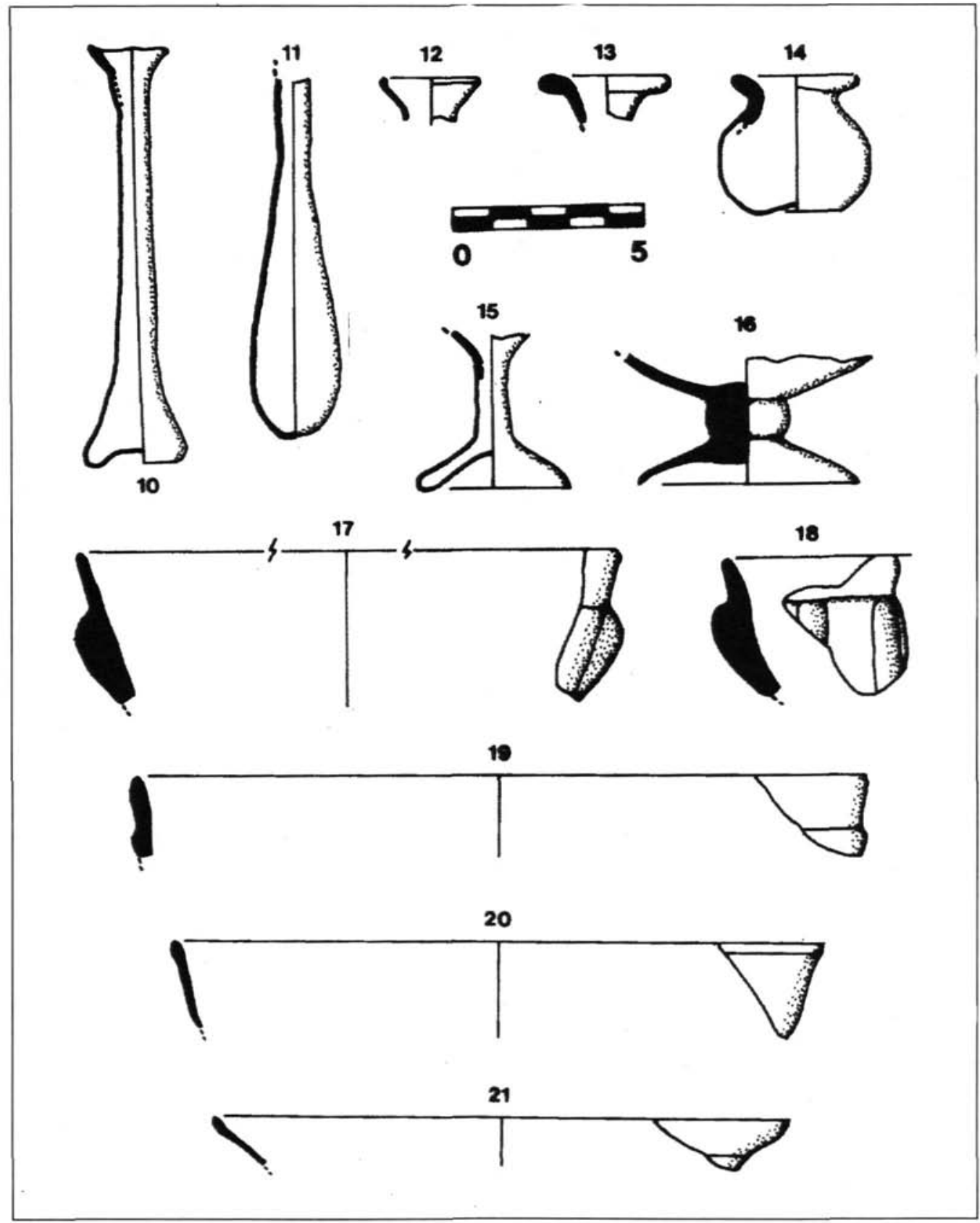

Figura. 2.- Núms. 10 al 14, ungüentarios (10, 11 y 14 pertenecientes a la colección E. Tello; 12 y 13 de La Bienvenida); Núm. 15, cáliz ha llado en Alhambra; Núm. 16, cántharos de La Bienvenida; Núms. 17 al 21, cuencos de La Bienvenida. 
En concreto nuestro ejemplar podría adscribirse a la variante 38a, característica del período claudio-neroniano, como parecen indicar las similitudes que presenta con dos cantharos de Conímbriga (Alarcao, 1976, 162, núm. 33 y 170, núm. 78-79) y otro de Ampurias. En concreto, el ejemplar ampuritano apareció en la incineración Patel-21, asociado a un ajuar datable en el reinado de Claudio (Almagro, 1955, 247-248, núm. 24), y está decorado con costillas, única diferencia observable respecto a la pieza de La Bienveni-da. En Baetulo han sido también hallados recipientes de esta forma (Flos, 1987, 39, fig. 8, núm. 34 y 84, fig. 59, núm. 301-302).

Con los números 17 y 18 recogemos dos cuencos decorados con costillas. Estos recipientes son característicos del S. I d.C., encontrándose en Pompeya (Borriello, 1986, 220, núm. 18), aunque es posible hallarlos todavía en la centuria siguiente. La popularidad de estas piezas se pone de manifiesto ante su aparición en todas las provincias del Imperio, e incluso fuera de sus fronteras, donde conforman el tipo 182 y 183 de Eggers (Eggers, 1951, 182-183, fig. 14). Técnicamente se confeccionaron mediante tres procesos distintos: moldeado, soplado y soplado en molde (Schuler, 1959, 47-52). La producción se encontraba muy diversificada, atestiguandose diversos talleres ubicados en distintas zonas. Los del Mediterráneo Oriental, estaban especializados en cuencos moldeados, que originariamente imitaban modelos en metal de la época de los Ptolomeos. En Italia ha de situarse otro foco, según a indicado Harden (Harden, 1958, 55). El vidrio soplado en molde es singular de la oficina romano-siria. Este taller habría surgido como resultado de la fuerte emigración de artesanos del Mediterráneo Oriental e Italia a mediados del S. I d.C. (Calvi, 1968, 101). Isings da a esta forma el número 3 de su clasificación, distinguiendo cuatro variantes (Isings, 1957, 17). La pieza 18 de La Bienvenida pertenecería a la categoría de los cuencos $3 \mathrm{a}$, siendo estos boles de poca profundidad, cuyo diámetro es superior a la alzada y están decorados con costillas alargadas que llegan hasta la base. Cronológicamente se documentan a partir de Augusto, siendo su etapa de florecimiento la claudio-neroniana hasta los flavios. El número 17 de nuestro catálogo se corresponde con la forma $3 \mathrm{~b}$, similar a la anterior, aunque de mayor profundidad. Temporalmente su producción es algo posterior, originándose con Claudio, pero su época de expansión coincide plenamente con la de su compañero. Las formas 3a y 3b de Isings son equiparables a los tipos 68 y69 de Morin-Jean (Morin-Jean, 1977, 122). Ante los múltiples paralelos peninsulares que podrían citarse, tanto para uno como para otro, nos remitiremos solamente a los procedentes de Conímbriga (Alarcao, 1965, 34, fig. 1, núm. 23 y 24 y 35, fig. 1, núm. 24), Alicante (Sánchez de Prado, 1984, fig. 7, núm. 1 y 4), Badalona (Flos, 1987, 31, fig, 6, núm. 32 y fig. 23, núm. 153-155), Mérida (Caldera, 1983, 30, fig. 8 b) y Carmona (Bendala, 1976, 116, lám. 50 , núm. 38 y 39).

Con el número 21 presentamos un cuenco bajo, característico de la romanidad tardía. Esta forma podría ser asimilable al tipo 116 de Isings y 70 de Morin-Jean, aunque existen serias discrepancias entre algunos autores. Alarcáo,quien en un primer momento estableció también esta semejanza (Alarcao, 1963b, 381 y ss.), rectifica posteriormente para separar estos recipientes de la forma Isings señalada, distinguiendo tres variantes según el perfil de la pared: A, de paredes rectas; B, sinuosas y C, carenadas (Alarcao, 1965, 110). Flos opina, sin embargo, que deben interpretarse como una derivación del tipo propuesto por Isings (Flos, 1987, 71-72). Las características morfológicas que los engloban son: boles de poca profundidad sin pie, con paredes muy abiertas y borde ligeramente engrosado. Pueden ser lisos o decorados con hilos blancos fundidos, líneas horizontales talladas, etc. Se fabricaron en vidrio verde de diversas tonalidades, así como en vidrio translúcido. La frecuencia de hallazgos en la Península Ibérica hace pensar en la presencia de talleres en nuestro suelo. Así lo señala, al menos, Sánchez de Prado para Lucentum, 


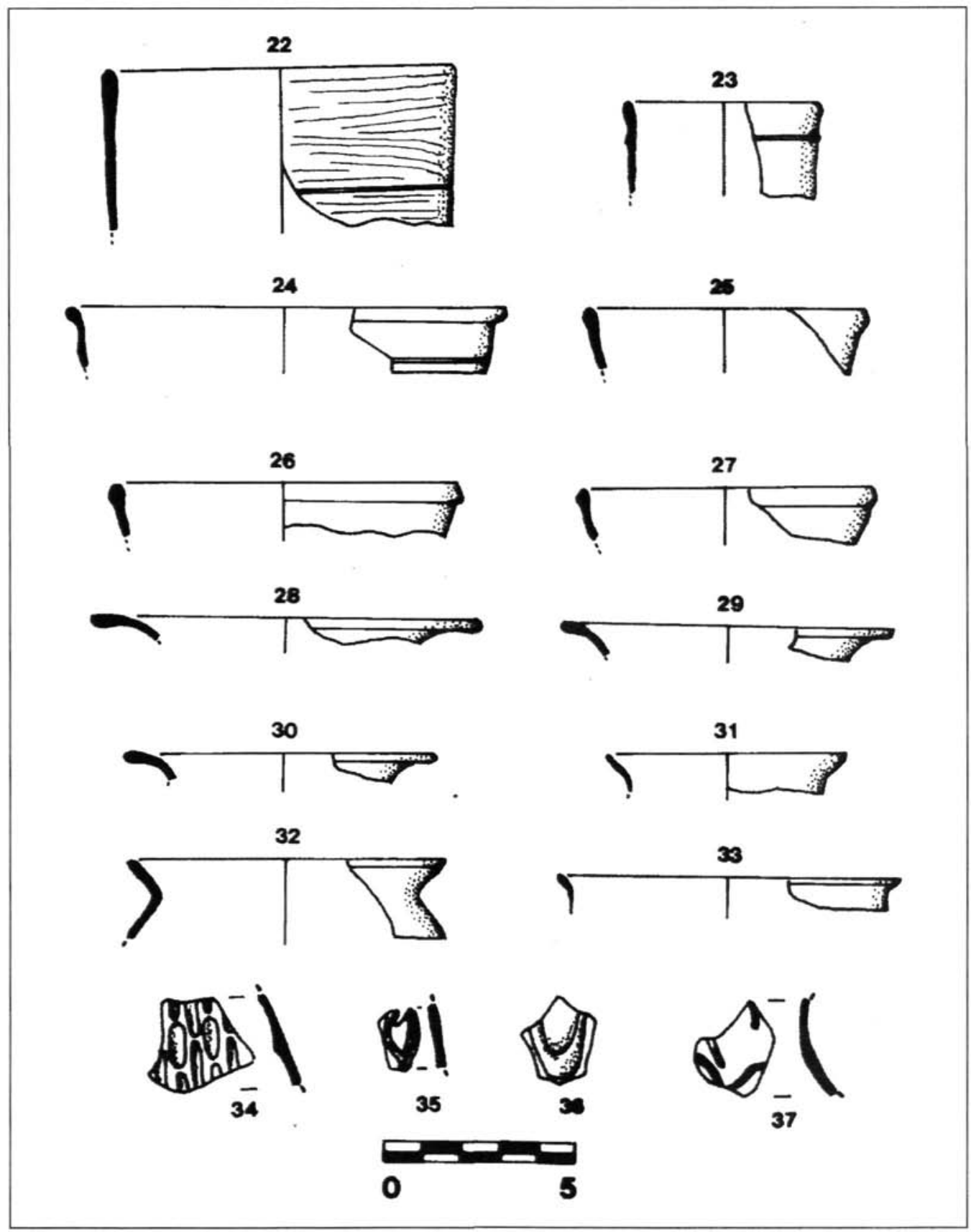

Figura 3.- Núms. 22 al 33, vasos y recipientes procedentes de La Bienvenida; Núms. 34 al 37, diversos fragmentos ornamentados de La Bienvenida. 
donde debió existir una oficina dedicada a la fabricación de los ejemplares lisos (Sánchez de Prado, 1984, 93). Yacimientos hispanos que han proporcionado piezas de este tipo son: Alconétar (Caballero, 1970, 54, fig. 20), Baetulo (Flos, 1987, 71-72, fig. 41, núm. 258-259), Cacia (Alarcao, 1963b, 381-386, fig. 3, núm. 1-13), Castro da Retorta (Alarcao, 1963a, 199, fig. 5, núm. 27), Conímbriga (Alarcao, 1976, 165, núm. 171-175), etc. En esta última ciudad portuguesa aparecen en niveles de los siglos IV-V d.C. (Alarcao, 1976, 193-194, núm. 203-213).

Los números 22 y 23 son dos vasos cilíndricos, recipientes muy populares durante las dos primeras centurias de nuestra era, hasta que pierden paulatinamente terreno frente al vaso troncocónico que se impondrá en el S. IV d.C. La temporalidad de estas piezas es, por tanto, amplia, y las variantes que presentan en sus bordes no sirven para subrayar matizaciones cronológicas. Estas formas suelen llevar decración de acanaladuras o incisiones, que son los motivos más habituales en esos siglos. Han aparecido en Alicante (Sánchez de Prado, 1984, fig. 6, núm. 11-14), Badalona (Flos, 1987, 36, fig. 5, núm. 59), Conímbriga (Alarcao, 1965, 115, fig. 7, núm. 191) y Carmona (Bendala, 1976, 115, lám. 49, núm. 29).

La número 24 es una taza datable en los siglos II-III d.C., según los resultados de excavaciones inglesas (Charlesworth, 1959, 49, fig. 7). Pertenece a un grupo bien definido de tazas, caracterizadas por su borde engrosado y decoradas con un cordón de vidrio en la parte superior del vaso. Esta forma se encuentra tanto en Occidente como en Oriente, y así, la encontramos en Chipre (Vessberg, 1956, fig. 42, núm. 28) y Dura-Europos (Clairmont, 1963, núm.231 y 232). En ocasiones la ornamentación se ve complementada con facetados,como en un ejemplar de Nijmegen (Harden, 1936, 124, fig. 2a), cordones serpentiformes, como en otro de Colonia (Fremersdore, 1959, lám. 58, núm. 52), e incluso con decoración pintada. Estas últimas, quizá fabricadas en el taller de Colonia. En Conímbriga han aparecido con gran profusión (Alarcao, 1965, 80, fig. 4, núm. 100-110).

Los bordes 26 y 27 pertenecen a boles poco profundos, de paredes curvas, pie anular y labio tubular, recogidos con el número 44a de Isings y el 84 de Morin-Jean. Son piezas que comienzan a fabricarse a partir de la mitad del S. I d.C., siendo características de la época Nerón-Vespasiano. Esta cronología de la primera centuria está confirmada en Camulodonum (Harden, 1947, 304, núm. 81) y Vindonisa (Berger, 1960, 74). En Hispania han sido hallados en Badalona (Flos, 1987, 36-37, fig. 5, núm. 63 y 64-65, fig. 32-33, núm. 203-210) y Conímbriga (Alarcao, 1965, 41-42, fig. 2, núm. 49 y 50), donde el tipo pervivió hasta al menos el S. II d.C.

Con los números 34-37 henos agrupado una serie de fragmentos decorados, para los que no podemos realizar ninguna matización morfológica segura debido a su estado fragmentario. La pieza 34 está ornamentada con depresiones longitudinales, obtenidas al moldear la pared del vaso con un instrumento, cuando el vidrio estaba aún caliente. Su difusión en Occidente se centra en el S. I d.C, como se atestigua en Vindonissa (Berger, 1960, 110 y ss.), para extenderse en la centuria siguiente por la región noroccidental, donde prevalecerá hasta el S. IV d.C. (Clairmont, 1963, 56-86), apareciendo en Karanis en casas del S. V d.C. Esta decoración se encuentra frecuentemente asociada a la forma 21 de Isings (Isings, 1957, 37-38), durante la segunda mitad del S. I d.C. Los paralelos hispanos consultados se fechan entre el S. I-II d.C. en el Tossal de Manises (Sánchez de Prado, 1984, 88, fig. 6, núm. 3 y 4) y fines del S I d.C. a fines del S. II d.C. en Conímbriga (Alarcao, 1976, 176, lám. 40, núm. 149, 157). El fragmento número 36 podría relacionarse con la forma 33 de Isings, a la que normalmente suele acompañar. Este tipo de recipiente no es muy común en Hispania, encontrándose abundantemente en Italia, Vindonissa y Canton Ticino, lo que ha llevado a Calvi a centrar su foco de producción en la Italia sep- 
tentrional (Calvi, 1968,58), tesis promulgada también por Berger, quien afirmaba que es allí donde debió ubicarse la primera oficina (Berger,1960, 43). Cronológicamente se originó en época claudia o claudio-neroniana y se mantuvo en boga hasta que decayó en la segunda mitad del S. II d.C. Esta temporalidad, sin embargo, es discutida por Alarcáo, para quien la fecha final habría que llevarla hasta el S. V d.C., a tenor de los ejemplares de Conímbriga (Alarcao, 1965, 26, fig. 1, núm. 13). El número 37 de nuestro inventario es un fragmento de pared con hilos en relieve, decoración en vigor desde finales del S. II hasta fines del S. IV d.C., aunque posiblemente existen precedentes del S. I d.C. en Conímbriga (Alarcao, 1965, 27, fig. 1, núm. 4). Fué originaria del taller sirio, desde donde se extendió a Chipre, Egipto y Renania, donde también existieron focos productores (Flos, 1987, 102).

El resto de las piezas del catálogo que no han sido inscritas en esta relación, es debido a su precario estado, lo que dificulta en extremo cualquier aproximación a su estudio. El número 20 posiblemente se trate de un vaso cónico de borde engrosado. Flos recoge en su estudio sobre los vidrios de Baetulo varios ejemplares, agrupándolos en el tipo D.1.a.3 de su trabajo (Flos, 1987, 79-80). La cronología de estas piezas es amplia. Los bordes 28 a 30 tienen paralelos en este mismo yacimiento, donde se fechan en tiempos de Domiciano (Flos, 1987, 47,fig. 17 , núm. 118 y 125). Los fragmentos 31 y 32 pertenecen a vasos, sin que podamos precisar si se tratan de vasos cilíndricos, troncocónicos, carenados, etc. Los bordes que se documentan en estas dos piezas, curvos con la parte superior recta, estuvieron en uso desde la mitad del S. I d.C. hasta el S. IV d.C.

\section{CONCLUSIONES}

Si bien, como dijimos en un principio, la colección de vidrios del Museo de Ciudad Real cabría ser calificada de modesta, debido al estado fragmentario de la mayoría de sus piezas, sin embargo, presenta el interés de cubrir una zona geográfica hasta hoy desconocida en los estudios relativos a estos materiales, con un número de ejemplares relativamente cuantioso. $\mathrm{Si}$ además tenemos en cuenta que el grueso de los mismos procede de una excavación científica, aunque adscritos a un área carente de estratigráfía, comprobaremos la importancia que en un futuro próximo adquirirán los vidrios romanos de esta provincia, cuando contemos con datos más precisos aportados por el yacimiento de La Bienvenida. Hasta entonces, y a modo de ensayo preliminar, ofrecemos algunas conclusiones inherentes al estado actual de nuestro conocimiento, señalando que éstas serán completadas cuando hallamos estudiados los nuevos ejemplares aparecidos en las últimas campañas de la estación mencionada.

En primer lugar, los vidrios de Ciudad Real documentan la línea evolutiva desarrollada en el Imperio, con muestras representativas de los tipos más característicos de cada momento, lo que en definitiva no es más que la plasmación del devenir histórico de esta zona y en concreto de La Bienvenida. Sobresalen, desde el punto de vista númerico, los ejemplares pertenecientes a las dos primeras centurias de nuestra era, que suponen más del ochenta por ciento de lo inventariado. En esta cronología altoimperial se alinean las botellas Isings 50 (números 5 al 9), el ungüentario de candelero núm. 10, el balsamario olliforme núm. 14, los vasos cilíndricos 22 y 23, la jarra 1 , etc. Entre los materiales inscritos en esta datación, además, son muy abundates los específicos del S. I d.C., así el cantharos 16, los ungüentarios tubulares 11 y 12 , los cuencos 17 y 18 , y los boles 26 y 27 . Esto quizá sea indicativo de la pujante vida, desarrollada en esta provincia, durante los momentos iniciales del Imperio, para pasar ya en el S. III a una especie de adormecimien- 
to, comprobable en el escaso número de recipientes fechados en ese momento y en la romanidad tardía. A una fase de transición entre el S. III d.C. y el S. IV cabe adscribir las jarras números 2,3 y 4 . Ya de tiempos plenamente tardorromanos son el cáliz 15 y el cuenco 21, este último posiblemente asociado a un taller hispano, con lo que sería la única pieza de todo el inventario susceptible de tal afirmación.

En cuanto al origen de nuestras piezas, no nos ha sido posible afiliarlas a talleres concretos, por lo que sólo indicaremos las áreas de influencia. Se documenta una doble corriente, occidental-oriental, palpable sobre todo en los materiales altoimperiales, no decantándose claramente a favor de ninguna de ellas, lo que es indicativo de un activo comercio. Respecto al S.IV-V d.C., queremos destacar el cáliz 15, característico producto de las oficinas orientales con incidencia minoritaria en Occidente, donde en ese momento se popularizaba el vaso troncocóncio. Frente a este hallazgo, no hemos logrado identificar ningún vaso troncocónico en nuestro estudio. Esta circunstancia, sin embargo, no creemos que sea enteramente significativa, pues posiblemente la incorporación de nuevos especímenes ofrecerá representantes de estos vasos tan extendidos en Hispania. Lo que sí podría indicar este cáliz, es la revitalización de la zona en fechas tardías. 


\section{BIBLIOGRAFIA}

Alarcao, J. y Alarcao, A., 1963a: "Vidros romanos do Museo de Martins Sarmento", Revista de Guimarâes, 73.

... 1963b: "Quatro pequenas coleccôes de vidros romanos", Revista de Guimarâes, 73.

... 1965: Vidros romanos de Conímbriga, Coimbra.

AlarCaO, J., 1968: "Vidros romanos de Museus do Alentejo e Algarve", Conímbriga, 7.

... 1976: Fouilles de Conimbriga, VI. Ceramiques diverses et verres, París.

Almagro, M., 1955: Las necrópolis de Ampurias, Barcelona.

... 1979: "La necrópolis de las parcelas 45 y 46 de Segóbriga”, Noticiario Arqueológico Hispánico, 7.

Alonso SANCHEZ, M.A., 1986-87: "Los osculatorios: Todavía algo más", Cuadernos de Prehistoria y Arqueología de la

Universidad Autónoma de Madrid, 13-14, Homenaje al Prof. Gratiniano Nieto, Vol. II.

BENDALA, M., 1976: La necrópolis romana de Carmona (Sevilla), Sevilla.

BERGER, L., 1960: Römische Gläser aus Vindonissa, Basileia.

BorRIELlo, M.R. et alii, 1986: Le collezioni del Museo Nazionale di Napoli, Roma.

Caballero, L., 1970: “Alconétar. En la vía romana de la plata, Garrovillas (Cáceres)", Excavaciones Arqueológicas en España, 80.

Caldera, M.P., Et Alli 1983: “Augusta Emerita, I”, Excavaciones Arqueológicas en España, 126.

CALvi, M.C., 1969: I vetri romani del Museo di Aquileia, Aquileia

CharlesworTh, D., 1959: "Roman glass in nothern Britain", Archaeologia Aeliana, 37.

... 1966: "Roman Square Bottles", Journal of Glass Studies, 8.

Clairmont, C.W., 1963: The excavations at Dura-Europos. Final report, IV, Part V. The glas vessels, New Haven.

EGGERS, H.J., 1951: Der römische Import im freien Germamanien, Hamburgo.

FLos, N., 1987: Baetulo. Els vidres, Monografies Badalonines, 10.

FREMERSDORF, F., 1959: Römische Gläser mit Fadenauflage in Köln, Colonia.

HaRDEN, D.B., 1936: Roman Glass from Karanis, Michigan.

... 1947: The Glass in Hawkes e Hull. First report on the excavations at Colchester, 1930-1939, Oxford.

IsINGS, C., 1957: Roman Glass from dated finds, Gröningen.

LANCEL, S., 1967: Verrerie antique de Tipasa, Paris.

Marcos, A. et alii, 1988: "Sepulturas romanas de Ucubi, actual Espejo (Córdoba)". Homenaje a Samuel de los Santos, Albacete.

MORIN-JEAN, 1977: La verrerie en Gaule sous l'empire romain, Paris.

RemeSAL, J., 1979: "La necrópolis sureste de Baelo", Excavaciones Arqueológicas en España, 104.

Roldan GomeZ, L., 1986-87: "La necrópolis de Mahora (Albacete)", Cuadernos de Prehistoria y Arqueologia de la U.A.M, 13-14, Homenaje al Prof. Gratiniano Nieto, Vol. II.

SANCHEZ DE Prado, M.D., 1984: "El vidrio romano en la provincia de Alicante", Lucentum, 3.

SCHULER, F., 1959: “Ancient glass-making techniques-The molding process”, Archeology, 21.

Vessberg, D., 1952: "Roman Glass in Cyprus", Opuscula Archaeologica,7

... 1956: The Swedish Cyprus Expedition, Vol IV, part 3: The Hellenistic and Roman Periods in Cyprus,

Estocolmo.

Villalba, P., 1983-84: “Vidres del Museu Bíblic de Montserrat”, Ampurias, 45-46. 